\title{
Final Editorial
}

\author{
Irene H. Frieze ${ }^{1}$
}

Published online: 7 November 2015

(C) Springer Science+Business Media New York 2015

I began formally serving as masthead editor of Sex Roles in January of 2007. Now, 9 years later, I publish my last issue. Having this opportunity to contribute to the field of feminist research in the social sciences and psychology has been a wonderful honor. Sex Roles has been one of the most, if not the most important journal in this field since its initiation in 1975. As we explain in the mission statement, Sex Roles is an interdisciplinary journal that publishes original research reports and theoretical articles that illuminate the underlying processes and consequences of gender role socialization, gendered perceptions and behaviors, and gender stereotypes. The journal has been published monthly since 1981. In 2014 we received submissions from 43 countries. We had 520 new submissions in 2014 along with many revisions. Thus, we are a very high volume journal that publishes papers on a broad array of topics.

One of my goals in editing the journal was to insure that the articles we published were excellent in terms of research design and analysis. I also wanted to help build theory in the area of gender research. All empirical papers were asked to provide a clear theory explaining the logic for why whatever behaviors were predicted by the authors would be expected to exist. Each paper was asked to provide formal, testable predictions based on this theoretical analysis. I feel that our increasing impact factors [now 1.735 for the 1 year impact factor, 2.067 for the 5 year impact factor and 9.7 cited and citing half-life] reflect this focus on theory and empirical excellence. Clearly, other researchers value our publications.

Irene H. Frieze

frieze@pitt.edu

1 University of Pittsburgh, Pittsburgh, Pennsylvania
Another goal was to further internationalize the journal. I did this in two major ways. First, we encouraged authors from many different countries to contribute as authors, as well as serving as reviewers and as members of our Editorial Board. By 2014, nearly $50 \%$ of the first authors of papers published that year in the journal were from countries other than the United States. We published one special issue on Spain, and expect the second issue of Spain to be published in 2016. We are working now on a special issue on Muslim women.

A second way the journal was internationalized was to be more sensitive to where samples came from. One of my basic editorial assumptions was that all gender-related behavior has a strong cultural component. It is impossible to understand that behavior without looking at those cultural assumptions. Authors were asked to identify the country in which their study was done in the Abstract as well as in the text of the paper. At least a page or two of the Introduction was devoted to explaining the cultural assumptions relating to gender and the issues being addressed in the paper. When authors cited studies done by others in building the theory and cultural background for their study, they were asked to explain where each study was done and how that study was relevant in understanding their particular sample. Some of these editorial concerns were explained in more detail in Frieze (2014) in an editorial on "The Importance of Samples."

Finally, another goal of my editorship was to encourage early career professionals and graduate students to be engaged in the research process. We invited students as well as less senior scholars to be reviewers for the journal. They served as regular reviewers and consistently provided professional and excellent reviews. I also tried to provide very detailed editorial feedback about changes that would be needed for a publishable paper in response to initial drafts that were sometimes very weak, but had interesting data and raised important research questions. I tried to be patient in allowing for multiple 
revisions if this was needed before a publishable paper was finally provided. Some researchers appreciated this long and detailed editorial process, and wrote letters thanking me. Others appeared frustrated and decided to submit elsewhere.

I have had a wonderful time and feel we have accomplished the goals I set out. I look forward now to seeing the journal continue under the able editorship of Jan Yoder. I do want to especially thank my Managing Editor, Susan Dittrich for all she has done for the journal, including establishing journal Facebook and Twitter accounts. For further information on these see www.facebook.com/SexRoles and www.twitter. com/sexroles. I also want to thank the many Associate Editors, Special Issue Editors, and reviewers for their important service to the journal.

\section{References}

Frieze, I. H. (2014). The importance of samples. Sex Roles, 70, 357-358. doi:10.1007/s11199-014-0376-6. 